\title{
Lipoprotein(a) Serum Levels and Apolipoprotein(a) Phenotypes in Children with Chronic Renal Disease ${ }^{1}$
}

\author{
U. QUERFELD, M. LANG, J. B. FRIEDRICH, B. KOHL, W. FIEHN, AND K. SCHÄRER \\ Departments of Pediatrics and Internal Medicine, University of Heidelberg, and Research Department, \\ Immuno AG, Heidelberg, Germany
}

\begin{abstract}
Lipoprotein(a) [Lp(a)] has recently been characterized as a genetically determined risk factor for atherosclerosis and thrombosis. Normally, $L p(a)$ serum levels are closely related to the apo(a) phenotype. We studied $L p(a)$ serum levels and apo(a) phenotypes in 136 young subjects, aged 0.8-24.7 $\mathrm{y}$, including patients with glomerular disease and normal renal function $(n=28)$, patients with chronic renal failure $(n=20)$, patients treated by hemodialysis $(n=10)$, peritoneal dialysis $(n=16)$, and renal transplantation $(n=23)$, and in controls $(n=39)$. Of all, 21 patients had proteinuria in the nephrotic range. The distribution of $L_{p}(a)$ levels in normal subjects was skewed to the left with $97 \%$ having levels below $300 \mathrm{mg} /$ L. A subpopulation with increased Lp(a) levels (13-42\%) could be detected in all groups with renal disease, and increased mean serum $L p(a)$ levels were found in patients with nephrotic range proteinuria, in patients with chronic renal failure, and in patients on peritoneal dialysis. Serum Lp(a) levels were not correlated with age, gender, type of renal disease, renal function or severity of proteinuria, but were correlated with the apo(a) phenotype. For a given phenotype, $L p(a)$ levels tended to be higher in patients than in controls. We conclude that increased $L p(a)$ serum levels are frequently found in young patients with chronic renal disease, possibly predisposing them to an increased risk for atherosclerosis and thrombosis. (Pediatr Res 34: 772-776, 1993)
\end{abstract}

Abbreviations

Lp(a), lipoprotein(a)

GFR, glomerular filtration rate

Chronic renal disease is often accompanied by severe dyslipidemia, a known risk factor for cardiovascular disease. In adults, cardiovascular disease is indeed by far the leading cause of death in patients on hemodialysis (1) and after renal transplantation (2), and an increased risk for atherosclerotic complications is assumed by many investigators for patients with unremitting nephrotic syndrome $(3,4)$. There are only limited data available concerning risk factors for atherosclerosis in children and adolescents with renal disease (5-7).

Received October 22, 1992; accepted June 29, 1993

Correspondence and reprint requests: Uwe Querfeld, M.D., Department of Pediatric Nephrology, University Children's Hospital, Joseph-Stelzmann-Str. 9, D50924 Köln 41, Germany.

Supported by the Deutsche Forschungsgemeinschaft (U.Q.).

' Parts of this study were presented at the Meeting of the European Atherosclerosis Society, Lissabon, Portugal, 1991 and at the International Conference on the Prevention of Atherosclerosis and Hypertension Beginning in Youth, Orlando, FL, 1992.
$\mathbf{L p}(\mathrm{a})$ is a cholesterol-rich lipoprotein resembling $\mathrm{LDL}$, but with a different protein composition, consisting of apo B-100 and apo(a). Increased blood concentrations of $L p(a)$ are strongly associated with an increased risk for atherosclerosis (8-10) and arterial and venous thrombosis (11). Notably in young patients, Lp(a) appears to be an independent risk factor for myocardial infarction (12). The proatherogenic and prothrombotic effects of $\mathrm{Lp}(\mathrm{a})$ are related to its interaction with macrophages of the arterial wall and to the structural similarity of apo(a) and plasminogen, leading to deposition of $L p(a)$ in atherosclerotic lesions and interference with the fibrinolytic system $(8,9,13)$.

In adult Caucasian populations, $\mathrm{Lp}(\mathrm{a})$ blood levels are usually low, i.e. the distribution of normal values is shifted to the left; blood levels above $250-300 \mathrm{mg} / \mathrm{L}$ indicate a significant risk for vascular complications, particularly in patients with elevated LDL cholesterol levels (13-15).

In normal individuals, $\mathrm{Lp}(\mathrm{a})$ serum levels are under genetic control and dependent on the phenotype of the apoprotein apo(a). According to Utermann et al. (16), seven phenotypes of different molecular weight can be differentiated by their relative mobilities to apo B-100 on electrophoresis; these have been designated F (faster than B-100), B (similar to B-100), S1, S2, S3, S4 (all slower than B-100), and 0 (not detectable). Serum levels of $L p(a)$ show an inverse correlation with the size of the apoprotein phenotype, i.e. small phenotypes (F, B, S1) are associated with high and larger phenotypes (S3, S4) with low serum levels of $L p(a)$ (16). Although Lp(a) levels for a given phenotype show considerable overlap, it was concluded that about $40 \%$ of the variability in the $\mathrm{Lp}(\mathrm{a})$ serum concentrations can be explained by the apo(a) phenotype (17). Other researchers have identified a greater number of apo(a) phenotypes, but the same inverse correlation between apo(a) size and $L p(a)$ serum concentration was found $(18,19)$.

$\mathrm{Lp}$ (a) can be detected in umbilical cord blood and serum of newborns (20-22), and a gradual rise in serum levels has been observed between the ages of 2 and 13 y (23). Previous studies in adults reported increased Lp(a) levels in patients with proteinuria (24-26) and in patients treated with hemodialysis (27) and renal transplantation (28). However, it remains unclear from these studies whether increases in $\operatorname{Lp}(a)$ are confined to individuals with a certain apo(a) phenotype. Neither Lp(a) serum levels nor apo(a) phenotypes have been studied in pediatric patients with renal disease.

We therefore determined Lp(a) serum levels and apo(a) phenotypes in children, adolescents, and young adults with chronic renal disease, including patients with glomerular disease and normal renal function, and with chronic renal failure and patients treated with hemodialysis, peritoneal dialysis, and renal transplantation.

\section{SUBJECTS AND METHODS}

Patients. A total of 136 subjects with an age range of 0.8 to 24.7 y were studied (Table 1). 
Table 1. Patient groups and serum Lp(a) levels*

\begin{tabular}{lccccccc}
\hline & CONTR & GD & CRF & HD & PD & TPL & NRP \\
\hline$n$ & 39 & 28 & 20 & 10 & 16 & 23 & 21 \\
Age (y) & $11.1 \pm 3.0$ & $12.5 \pm 4.5$ & $11.3 \pm 5.1$ & $13.7 \pm 4.9$ & $11.1 \pm 4.5$ & $14.8 \pm 5.9$ & $11.3 \pm 5.2$ \\
Lp(a)(mg/L) & $80 \pm 81$ & $157 \pm 222$ & $399 \pm 424 \dagger$ & $216 \pm 241$ & $193 \pm 137 \dagger$ & $129 \pm 145$ & $271 \pm 296 \dagger$ \\
(median) & $(59)$ & $(53)$ & $(221)$ & $(146)$ & $(170)$ & $(79)$ & $(182)$ \\
$n>300(\%) \ddagger$ & 1 & 5 & 8 & 2 & 3 & 3 & 8 \\
& $(2.6)$ & $(17.9)$ & $(40)$ & $(20)$ & $(18.8)$ & $(13)$ & $(42.1)$ \\
\hline
\end{tabular}

* CONTR, controls; GD, glomerular disease; CRF, chronic renal failure; HD, hemodialysis; PD, peritoneal dialysis; TPL, transplantation; NRP, nephrotic range proteinuria.

+ Significantly different from the control group $(p<0.05)$.

$¥$ Number of subjects (and \% of group total) with Lp(a) serum levels $>300 \mathrm{mg} / \mathrm{L}$.

Table 2. Lipoprotein lipid and apolipoprotein levels*

\begin{tabular}{lccccccc}
\hline & CONTR & \multicolumn{1}{c}{ GD } & \multicolumn{1}{c}{ CRF } & HD & PD & TPL & NRP \\
\hline TG $(\mathrm{mmol} / \mathrm{L})$ & $1.25 \pm 0.74$ & $2.55 \pm 3.38 \dagger$ & $2.24 \pm 1.78 \dagger$ & $2.03 \pm 0.8 \dagger$ & $2.06 \pm 1.05 \dagger$ & $1.74 \pm 0.82 \dagger$ & $3.58 \pm 3.96 \ddagger$ \\
Chol $(\mathrm{mmol} / \mathrm{L})$ & $4.29 \pm 0.67$ & $7.01 \pm 5.61 \ddagger$ & $5.40 \pm 1.84 \dagger$ & $4.81 \pm 1.06$ & $6.05 \pm 1.78 \ddagger$ & $5.53 \pm 1.22 \ddagger$ & $8.25 \pm 6.03 \ddagger$ \\
VLDL-C (mmol/L) & $0.49 \pm 0.34$ & $1.50 \pm 3.54 \dagger$ & $1.11 \pm 1.06 \dagger$ & $0.96 \pm 0.54 \dagger$ & $1.11 \pm 0.75 \dagger$ & $0.72 \pm 0.39 \dagger$ & $2.30 \pm 4.11 \ddagger$ \\
LDL-C (mmol/L) & $2.66 \pm 0.67$ & $4.34 \pm 2.74 \ddagger$ & $3.31 \pm 1.37 \dagger$ & $3.03 \pm 0.80$ & $3.98 \pm 1.22 \ddagger$ & $3.67 \pm 1.09 \ddagger$ & $4.89 \pm 2.59 \ddagger$ \\
HDL-C (mmol/L) & $1.16 \pm 0.26$ & $1.14 \pm 0.36$ & $0.98 \pm 0.26 \dagger$ & $0.83 \pm 0.26 \ddagger$ & $0.96 \pm 0.26 \dagger$ & $1.16 \pm 0.28$ & $1.03 \pm 0.44$ \\
Apo A-l (g/L) & $1.49 \pm 0.24$ & $1.73 \pm 0.51$ & $1.52 \pm 0.27$ & $1.32 \pm 0.41 \dagger$ & $1.54 \pm 0.30$ & $1.57 \pm 0.39$ & $1.73 \pm 0.56$ \\
Apo B (g/L) & $0.95 \pm 0.36$ & $1.71 \pm 0.84 \ddagger$ & $1.62 \pm 0.54 \dagger$ & $1.42 \pm 0.52 \dagger$ & $1.92 \pm 0.87 \dagger$ & $1.59 \pm 0.53 \ddagger$ & $1.99 \pm 0.76 \ddagger$ \\
\hline
\end{tabular}

* Group abbreviations are the same as in Table 1. TG, triglycerides; Chol, cholesterol; VLDL-C, cholesterol in the VLDL fraction; LDL-C, cholesterol in the LDL-fraction; HDL-C, cholesterol in the HDL-fraction.

$\dagger p<0.05$ compared with the control group.

$\ddagger p<0.01$ compared with the control group.

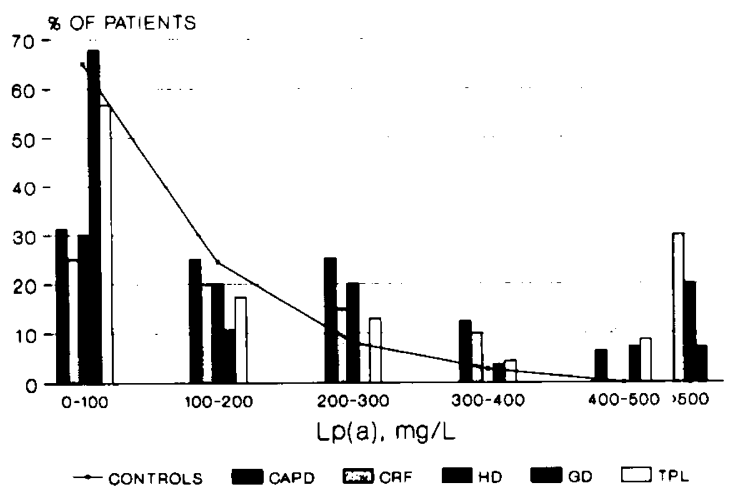

Fig. 1. Distribution of Lp(a) serum levels in controls (straight line) and in the different patient groups (bars). Patients with nephrotic range proteinuria are included in the groups GD (glomerular disease), CRF (chronic renal failure), and TPL (transplantation).

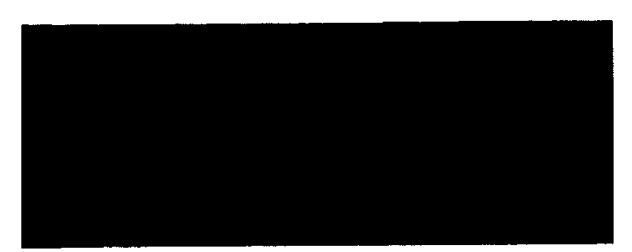

Fig. 2. Phenotyping of apo(a) isoforms. Phenotyping was performed as described with six sera running (from left to right) in lanes $1,3,4,5$, 7 , and 8; standards with known phenotypes were run in lanes 2 and 6 . The standards include (bands shown from above to below) S3, S2, S1, and $B$. The sera were classified (from left to right) as S4S3, S4S2, 0, S4, S4S2, and S4S3. The corresponding Lp(a) serum levels were 100 , standard, $100,0,160$, standard, 330 , and $340 \mathrm{mg} / \mathrm{L}$.

Normal control subjects $(n=39)$. These children were seen in the outpatient department for minor illnesses and had normal renal function (GFR $>80 \mathrm{~mL} / \mathrm{min} / 1.73 \mathrm{~m}^{2}$ ).

Glomerular disease $(n=26)$. The patients in this group had a variety of glomerular diseases for $6.5 \pm 6.0 \mathrm{y}$ and normal renal function (GFR $>80 \mathrm{~mL} / \mathrm{min} / 1.73 \mathrm{~m}$ ). Sixteen patients had mild proteinuria (145 $\left.\pm 211 \mathrm{mg} / \mathrm{m}^{2} / \mathrm{d}\right)$; histologic diagnoses in these patients included minimal change disease (13), IgA nephropathy (2), and endoextracapillary glomerulonephritis (1). Ten patients had proteinuria in the nephrotic range $\left(>1 \mathrm{~g} / \mathrm{m}^{2} / \mathrm{d}\right)$; diagnoses were minimal change disease (6), Wegener's granulomatosis (1), focal segmental glomerulosclerosis (1), membranoproliferative glomerulonephritis (1), and mesangial glomerulonephritis (1).

Chronic renal failure $(n=20)$. These patients had decreased renal function (GFR $<70 \mathrm{~mL} / \mathrm{min} / 1.73 \mathrm{~m}^{2}$ ) for $6.9 \pm 4.3 \mathrm{y}$. Histologic diagnoses included autoimmune vasculitis (1), congenital nephrosis (1), focal-segmental glomerulosclerosis (1), Henoch-Schoenlein purpura (1), hemolytic-uremic syndrome (4), IgA nephropathy (2), membranoproliferative glomerulonephritis (1), oligomeganephronia (1), obstructive uropathy (3), renal hypoplasia/dysplasia (4), and segmental hypoplasia (1). Eight patients had proteinuria in the nephrotic range (1.0 to 34 $\mathrm{g} / \mathrm{m}^{2} / \mathrm{d}$ ).

Peritoneal dialysis $(n=16)$. All patients were treated with continuous peritoneal dialysis for a total of $1.7 \pm 1.0 \mathrm{y}$ and were anuric.

Hemodialysis $(n=10)$. All patients were treated with hemodialysis for a total of $3.5 \pm 5.4$ y and were anuric.

Renal transplantation $(n=23)$. The patients in this group had a functioning renal transplant for 0.1 to $12.3 \mathrm{y}$, mean $3.6 \pm 3.3$ y. Renal function varied between 14 and $167 \mathrm{~mL} / \mathrm{min} / 1.73 \mathrm{~m}^{2}$ (mean $67 \pm 41 \mathrm{~mL} / \mathrm{min} / 1.73 \mathrm{~m}^{2}$ ). Twenty-one patients had mild proteinuria (31 to $976 \mathrm{mg} / \mathrm{m}^{2} / \mathrm{d}$ ) and three patients had proteinuria in the nephrotic range $\left(1.7,2.5\right.$, and $\left.4.9 \mathrm{~g} / \mathrm{m}^{2} / \mathrm{d}\right)$. All patients were treated with corticosteroids and azathioprine, and all but three received cyclosporin $\mathrm{A}$.

Nephrotic range proteinuria $(n=21)$. Patients in this group belonged to the glomerular disease group $(n=10)$, the chronic renal failure group $(n=8)$, and the renal transplantation group $(n=3)$ and were separately evaluated because of the presence of proteinuria in the nephrotic range $\left(1.0-34 \mathrm{~g} / \mathrm{m}^{2} / \mathrm{d}\right.$, mean $7.6 \pm$ $\left.9.3 \mathrm{~g} / \mathrm{m}^{2} / \mathrm{d}\right)$.

Methods. The study was approved by the Ethical Committee of the Medical Faculty of the University of Heidelberg. Informed consent was obtained from all subjects participating in the study.

Lipoprotein profile. Venous blood was drawn in the morning from nonfasting subjects. Total triglycerides, total cholesterol, and cholesterol in the VLDL fraction, LDL fraction, and HDL fraction were measured by routine enzymatic methods (29). Apo 
Table 3. Apo(a) phenotypes and $L p(a)$ serum levels (mean $\pm S D$ ) in 91 patients and 39 controls

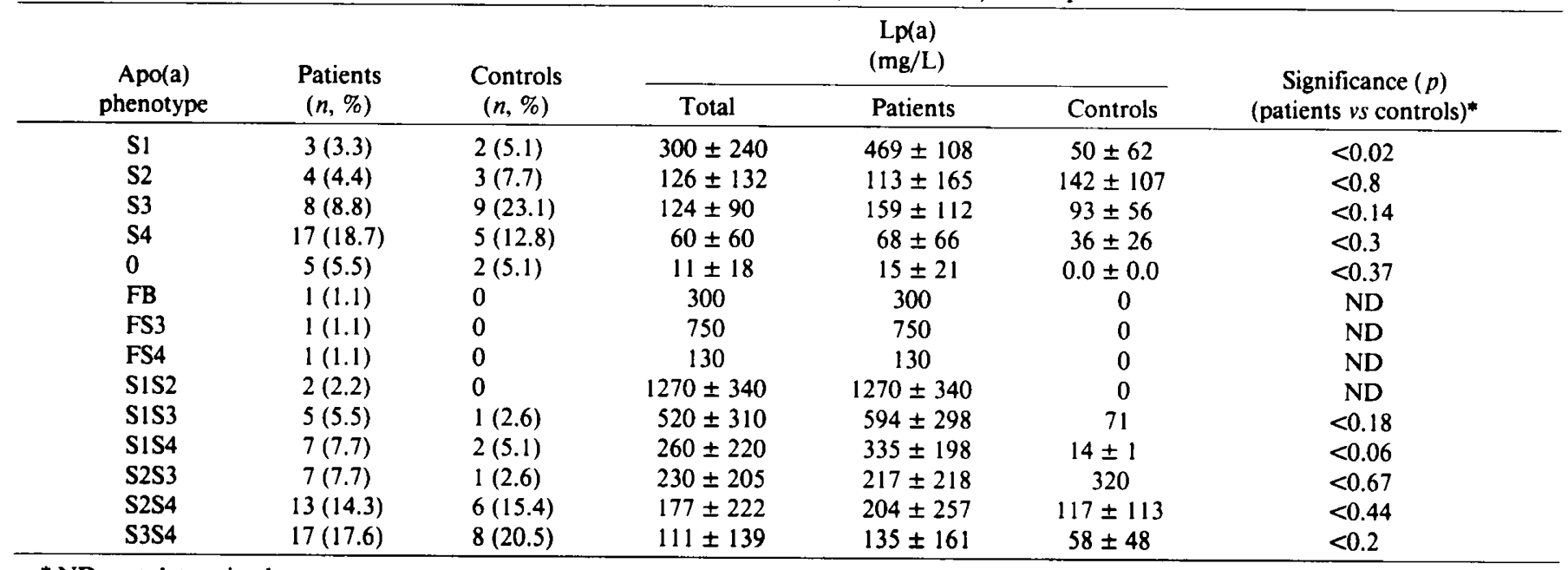

* ND, not determined.

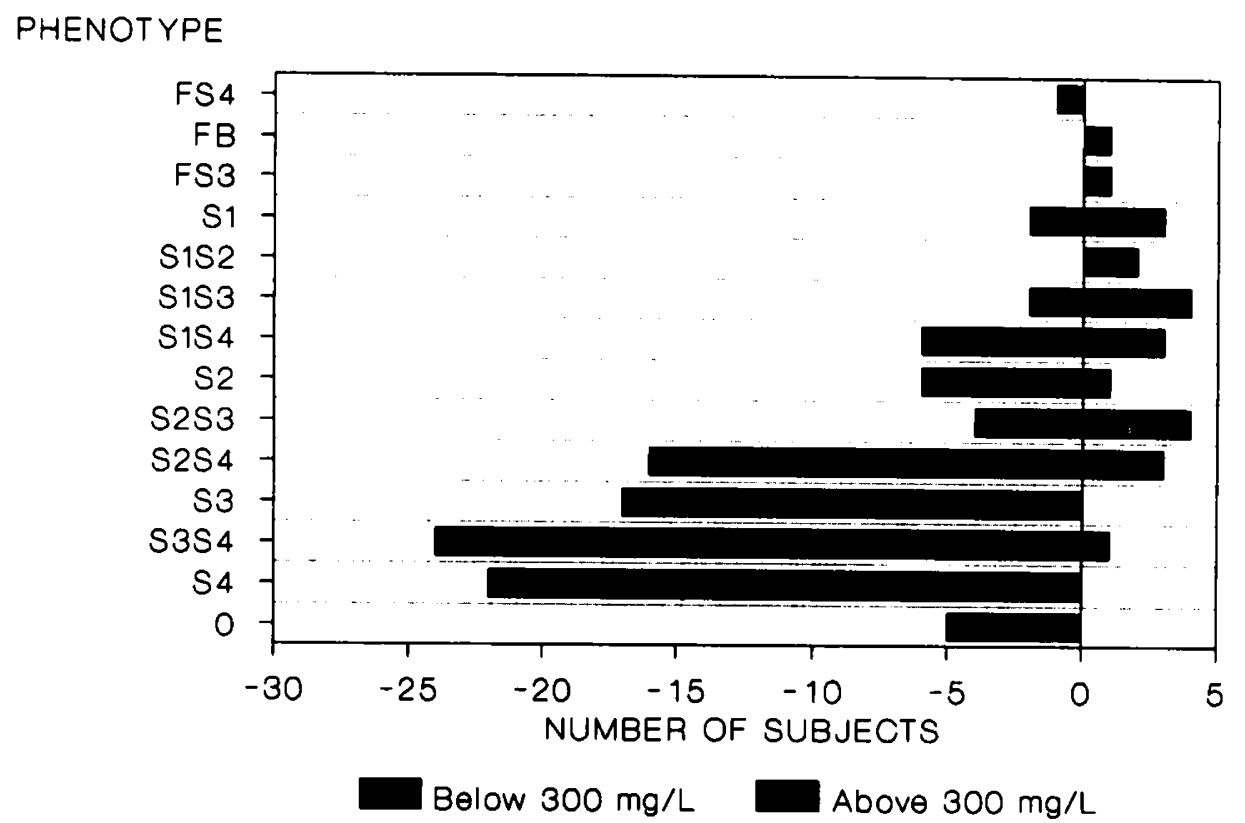

Fig. 3. Distribution of patients grouped by apo(a) phenotypes at a cutoff $L p(a)$ serum concentration of $300 \mathrm{mg} / \mathrm{L}$. Data were from 91 patients and 39 controls. Only one subject in the control group had an $\mathrm{Lp}(\mathrm{a})$ serum level $>300 \mathrm{mg} / \mathrm{L}$.

A-I and apo B were measured by turbidimetric methods (Turbitimer, Behring, Marburg, Germany).

$L p(a)$ serum levels. $L p(a)$ in serum was measured by enzyme immunoassay (Biopool, Umea, Sweden) and by a one-step ELISA method (Immuno, Heidelberg, Germany), which showed a good correlation $(r=0.897)$. Results are reported for the enzyme immunoassay. All samples were measured in duplicates. For the enzyme immunoassay, intraassay variability was $6 \%$; interassay variability was $4 \%$ for levels $>10 \mathrm{mg} / \mathrm{dL}$.

Apo(a) phenotype. The apo(a) phenotypes were separated by SDS-PAGE using a commercially available $4-15 \%$ gradient gel (PHAST-System, Pharmacia, Freiburg, Germany). This method was modified for $\mathrm{Lp}(\mathrm{a})$ detection according to Molinari et al. (30), using a polyclonal sheep anti-Lp(a) antibody (Immuno). Determination of phenotypes was performed by comparison with standard phenotypes prepared from individual donors (Immuno).

Renal function. Renal function was estimated by measuring the creatinine clearance in patients with urine output, as well as by calculation of the GFR according to Schwartz et al. (31) in all patients and controls.

Proteinuria. Urinary protein was measured using the Coomassie reagent (Bio-Rad, Munich, Germany).
Statistical evaluation. Statistical significance of differences between variables in the groups was calculated by the KruskallWallis test and the Mann-Whitney test [Lp(a) levels for given phenotypes]. Testing for correlations of variables was performed by calculation of the Spearman rank correlation coefficient. Differences in apo(a) phenotype distribution were compared by the $\chi^{2}$ test.

\section{RESULTS}

Lipoprotein lipids and $L p(a)$. Elevated serum levels of lipoprotein lipids and $L p(a)$ were found in all groups studied (Tables 1 and 2). Significant increases in mean $L p(a)$ levels were found only in the chronic renal failure, nephrotic range proteinuria, and peritoneal dialysis groups (Table 1). The distribution of $\mathrm{Lp}(\mathrm{a})$ levels in normal subjects was skewed to the left with $97 \%$ of patients having levels below $300 \mathrm{mg} / \mathrm{L}$ (Fig. 1) and only one patient with a level above $300 \mathrm{mg} / \mathrm{L}(320 \mathrm{mg} / \mathrm{L})$. In contrast, the distribution of $L p(a)$ values in the patient groups was scattered with a shift to the right, and a subpopulation (up to $42 \%$ ) with increased Lp(a) levels was found in all groups of patients with chronic renal disease (Table 1, Fig. 1). 
Correlations. The following variables were tested for correlations with $\mathrm{Lp}(\mathrm{a})$ serum levels: age, gender, weight, height, body mass index, C-reactive protein level, serum creatinine level, serum total protein level, GFR, and proteinuria. None of these variables were significantly correlated with $L p(a)$ levels, regardless of whether the groups were tested individually or all patients were combined.

Apo(a) phenotypes. Phenotyping was successfully performed in 130 subjects (Fig. 2). A single band phenotype was found in $51(39.2 \%)$ and a double band phenotype in $72(55.3 \%)$; no band (phenotype " 0 ") could be detected in seven sera (5.4\%). The distribution of phenotypes found in patients and controls was not significantly different $\left(\chi^{2}=8.9, p<0.7\right)$. As has been reported previously in normal subjects (14-17), there was a strong correlation of the apo(a) phenotype with the serum level of $L p(a)$ (Table 3). This was most clearly evident in single-band phenotypes; double-band phenotypes were associated with $\mathrm{Lp}(\mathrm{a})$ levels that most likely reflect an additive effect of the two alleles (14, 16). At a cutoff serum $\mathrm{Lp}$ (a) level of $300 \mathrm{mg} / \mathrm{L}$, a significant difference in apo(a) phenotype distribution was calculated $\left(\chi^{2}=\right.$ $69.0 ; p<0.0001)$. Figure 3 shows that phenotypes $0, \mathrm{~S} 3$, and S4 were exclusively associated with $\mathrm{Lp}(\mathrm{a})$ levels below $300 \mathrm{mg} / \mathrm{L}$. However, for most given phenotypes, patients with chronic renal diseases had higher $\mathrm{Lp}(\mathrm{a})$ levels, although this finding was not statistically significant in all cases, possibly because of the limited number of comparable subjects (Table 3 ).

$L p(a)$ serum levels were repeatedly evaluated in 10 patients and showed very little variability. In six patients, $L p(a)$ levels were measured before and after transplantation. Two patients showed an increase in $\mathrm{Lp}$ (a) (from 690 and 140 to 840 and 480 $\mathrm{mg} / \mathrm{L}$ ), and three patients showed a decrease (from 200,160, and 610 to 90,80 , and $120 \mathrm{mg} / \mathrm{L}$ ); one patient had an unmeasurable level before and after transplantation. No change in phenotype was noted before and after transplantation.

\section{DISCUSSION}

The present study demonstrates that high $L p(a)$ serum levels are frequently found in young patients with chronic renal disease. Normal children and adolescents had serum levels of $L p(a)$ that were similarly distributed but somewhat lower than those reported in adult subjects $(8-13)$. Elevated $L p(a)$ levels were present in $13-42 \%$ of patients in all groups studied and were not associated with a particular renal disease or the patient's age, gender, degree of renal function, or the severity of proteinuria. Nonfasting conditions may have affected the serum triglyceride levels in our patients, but an effect on Lp(a) serum levels seems unlikely in view of the recent literature (32).

Previous studies have raised suspicions that serum $L p(a)$ levels can be affected by chronic renal diseases and metabolic disturbances. Elevations in $\mathrm{Lp}(\mathrm{a})$ serum levels have been documented in adults with proteinuria (24-26), adults with end-stage renal failure treated by hemodialysis (27), renal allograft recipients (28), and children (33) and adults (34) with diabetes mellitus. In addition, alcohol intake (35) and possibly treatment with corticosteroids (25) may have an effect on serum Lp(a) levels.

From the data of Karradi et al. (24) who found a correlation of $L p(a)$ serum levels with the amount of urinary protein loss, it could be hypothesized that an increase in hepatic Lp(a) production might be the cause of increased $\mathrm{Lp}(\mathrm{a})$ levels in patients with the nephrotic syndrome, analogous to the increased hepatic production of VLDL. We could not demonstrate a similar relationship, whether the patients with proteinuria in each group were analyzed separately or pooled together; moreover, increases in $\mathrm{Lp}(\mathrm{a})$ were not confined to patients with proteinuria. The fact that $L p(a)$ levels are not correlated with lipoprotein lipid levels has been found in other studies (8-11) and may be further evidence of an altogether different metabolism of this lipoprotein. Our data also indicate that increases in $\mathrm{Lp}(\mathrm{a})$ are not dependent on the degree of glomerular function, inasmuch as no correlation was observed with the GFR.

The impression that renal diseases may have a profound influence on $L p(a)$ is further underscored by the observation of changes in $\mathrm{Lp}(\mathrm{a})$ serum levels (but not phenotypes) before and after renal transplantation. It cannot be ruled out that these changes may have been induced by immunosuppressive drug treatment. Webb et al. (28) have recently demonstrated elevated $\mathrm{Lp}$ (a) levels in $29 \%$ of adult renal allograft recipients; serum levels were significantly higher in patients taking cyclosporin. In the present study, the effect of treatment with steroids and cyclosporin A could not be separately evaluated because almost all of our patients were treated with both drugs. Apart from immunosuppressive treatment (transplanted patients), our patients were treated with a variety of medications, including antihypertensive drugs, phosphate binders, vitamin D analogues, and erythropoietin. However, we could not detect a relationship between any particular medication and increased Lp(a) levels. It is known that $\mathrm{Lp}(\mathrm{a})$ serum levels are not affected by diet and most lipid-lowering drugs.

From the studies of Utermann et al. (16) and others (17-19) it is apparent that small apo(a) phenotypes are associated with high $L p(a)$ levels and larger apo(a) phenotypes with lower levels. Our data indicate that this relationship is also present in patients with chronic renal diseases. However, $\mathrm{Lp}(\mathrm{a})$ serum levels for almost all phenotypes were shifted toward higher values; therefore, elevated $\mathrm{Lp}$ (a) levels $>300 \mathrm{mg} / \mathrm{L}$ with a high atherogenic potential occurred in patients with double-band phenotypes and with the smaller phenotypes $\mathrm{F}, \mathrm{B}, \mathrm{S} 1$, and $\mathrm{S} 2$, but were absent in phenotypes S3 and S4. The physiologic mechanisms of Lp(a) regulation are yet unknown; however, the present study shows that chronic renal diseases may interfere with the normal synthesis and/or catabolism of $\operatorname{Lp}(\mathrm{a})$, regardless of the apo(a) phenotype. The kidney might have a role in the catabolism of $L p(a)$ (36). Because of its strong affinity to glycosaminoglycans (37), Lp(a) could bind to glomerular basement membranes; by inhibiting fibrinolysis, $\mathrm{Lp}(\mathrm{a})$ could thus play a role in the progression of renal disease (26).

In patients with chronic renal diseases, further prospective studies are needed to evaluate the clinical significance of increased $L p(a)$ levels. Thus, high $L p(a)$ levels might help identify those patients with chronic renal disease with an increased risk for atherosclerotic and thrombotic complications. This may be of special importance in young patients with potentially lifelong exposure to this risk factor.

Acknowledgment. The authors thank Dr. F. Schaefer, University Children's Hospital, Heidelberg, for help with the statistical evaluation.

\section{REFERENCES}

1. Brunner FP, Brynger H, Chantler C, Donckerwolcke RA, Hatzway RA, Jacobs C, Selwood NH, Wing AJ 1979 Combined report on regular dialysis and transplantation in Europe. Proc Eur Dial Transplant Assoc 16:4-104

2. Brunner FP, Broyer M, Brynger H, Challah S, Dykes SR, Fassbinder W, Oules R, Rizzoni G, Selwood NH, Wing AJ 1988 Survival on renal replacement therapy: data from the EDTA registry. Nephrol Dial Transplant 2:109-122

3. Mallick NP, Shore CD 1981 The nephrotic syndrome and ischemic heart disease. Nephron 27:54-57

4. Wass V, Cameron JS 1981 Cardiovascular disease and the nephrotic syndrome: the other side of the coin. Nephron 27:58-61

5. Papadopoulou ZL, Sandler P, Tina LU, Jose PA, Calcano PL 1985 Hyperlipidemia in children with chronic renal insufficiency. Pediatr Res 15:887-891

6. Querfeld U, LeBoeuf RC, Salusky IB, Nelson P, Laidlaw S, Fine RN 1991 Lipoproteins in children treated by continuous peritoneal dialysis. Pediatr Res 29:155-159

7. Van Gool S, van Damme-Sombaerts R, Cobbaert C, Proesmans W, Eggermont E 1991 Lipid and lipoprotein abnormalities in children on hemodialysis and after renal transplantation. Transplant Proc 23:1375-1377

8. Dahlen GH, Guyton JR, Attar M, Farmer JA, Kautz JA, Gotto AM 1986 Association of levels of lipoprotein Lp(a), plasma lipids, and other lipoproteins with coronary artery disease documented by angiography. Circulation 74:759-765

9. Rath M, Niendorf A, Reblin T, Dietel M, Krebber HJ, Beisiegel U 1989 
Detection and quantification of lipoprotein(a) in the arterial wall of 107 coronary bypass patients. Arteriosclerosis 9:579-592

10. Murai A, Miyahava T, Fujimoto N, Matsuda M, Kameyana M 1986 Lp(a) lipoprotein as a risk factor for coronary heart disease and cerebral infarction. Atherosclerosis 59:199-204

11. Hoff HF, Beck GJ, Skibinski Cl, Jüngens G, O'Neil J, Kramer J, Little B 1988 Serum Lp(a) level as a predictor of vein graft stenosis after coronary artery bypass surgery in patients. Circulation 77:1238-1244

12. Sandkamp M, Funke H, Schulte H, Köhler E, Assmann G 1990 Lipoprotein(a) is an independent risk factor for myocardial infarction at young age. Clin Chem 36:20-23

13. Scanu AM, Fless GM 1990 Lipoprotein(a) Heterogeneity and biological relevance. J Clin Invest 85:1709-1715

14. Kostner GM, Avogaro P, Cazzolato G, Marth E, Bittolo-Bon G, Quinci GB 1981 Lipoprotein LP(a) and the risk for myocardial infarction. Atherosclerosis 38:51-61

15. Armstrong VW, Cremer P, Eberle E, Manke A, Schulze F, Wieland H, Kreuze H, Seidel D 1986 The association between serum Lp(a) concentrations and angiographically assessed coronary atherosclerosis. Atherosclerosis 62:249257

16. Utermann G, Menzel HJ, Kraft HG, Dubs HC, Kemmler HG, Seitz C 1987 Lp(a) glycoprotein phenotypes. Inheritance and relation to $L p(a)$ lipoprotein concentrations in plasma. J Clin Invest 80:558-565

17. Boerwinkle E, Menzel HJ, Kraft HG, Utermann G 1989 Genetics of the quantitative Lp[a] lipoprotein trait. III. Contribution of Lp[a] glycoprotein phenotypes to normal lipid variation. Hum Genet 82:73-78

18. Gaubatz JW, Ghanem KI, Guervara J, Nava ML, Patsch W, Morrisett JD 1990 Polymorphic forms of human apolipoprotein[a]:inheritance and relationship of their molecular weights to plasma levels of lipoprotein[a]. J Lipid Res 31:603-613

19. Helmhold M, Bigge J, Muche R, Mainoo J, Thiery J, Seidel D, Armstron VW 1991 Contribution of the apo[a] phenotype to plasma Lp[a] concentrations shows considerable ethnic variation. J Lipid Res 32:1919-1928

20. Strobl W, Widhalm K, Kostner G, Pollak A 1983 Serum lipoproteins and lipoprotein(a) during the first week of life. Acta Paediatr Scand 72:505-509

21. Abe A, Maeda S, Mahino K, Seishima M, Shimokawa K, Nomad A, Kawade M 1988 Enzyme-linked immunosorbent assay of lipoprotein(a) in serum and cord blood. Clin Chim Acta 177:31-40

22. Van Biervliet JP, Michiels G, Rosseneu M 1991 Quantification of lipoprotein(a) in dried blood spots and screening for above-normal lipoprotein(a) concentrations in newborns. Clin Chem 37:706-708
23. Kostner GM, Czinner A, Pfeiffer KH, Bihari-Varga M 1991 Lipoprotein(a) concentrations as risk indicators for atherosclerosis. Arch Dis Child 66:10541056

24. Karadi I, Romics L, Palos G, Dorman J, Kaszas I, Hesz A, Kostner GM 1989 Lp(a) lipoprotein concentration in serum of patients with heavy proteinuria of different origin. Clin Chem 35:2121-2123

25. Takegoshi T, Kitoh C, Haba T, Hirai J, Wakasugi T, Saga T, Yamazaki Y Mabuchi H 1991 A study of the clinical significance of lipoprotein(a) in nephrotic syndrome. Jpn J Med 30:21-25

26. Thomas ME, Freestone A, Varghese Z, Persaud JW, Moorhead JF 1992 Lipoprotein(a) in patients with proteinuria. Nephrol Dial Transplant 7:597601

27. Parra HJ, Mezdour H, Cachera C, Dracon M, Tacquet A, Fruchart JC 1987 Lp(a) lipoprotein in patients with chronic renal failure treated by hemodialysis. Clin Chem 33:721

28. Webb AT, Plant M, Reaveley DA, O'Donnell, Luck VA, O'Connor B, Seed M, Brown EA 1992 Lipid and lipoprotein(a) concentrations in renal transplant patients. Nephrol Dial Transplant 7:636-641

29. Kohlmeier M 1986 Vereinfachte Lipoproteinanalyse mit der Ultrazentrifuge Ärztl Laboratorium 32:46-52

30. Molinari E Pichler P, Reschny A, Kostner G 1990 Lp(a) phenotyping on the Phast system (Pharmacia). 55th annual meeting of the European Atherosclerosis Society, May 17-19, Brugge, Belgium (abstr)

31. Schwarz GJ, Haycock GB, Edelmann CM, Spitzer A 1976 A simple estimate of glomerular filtration rate in children derived from body length and plasma creatinine. Pediatrics 58:259-263

32. Pfaffinger D, Schuelke J, Kim C, Fless GM, Scanu AM 1991 Relationship between apo[a] isoforms and Lp[a] density in subjects with different apo[a] phenotype: a study before and after a fatty meal. J Lipid Res 32:679-683

33. Bruckert E, Davidoff $P$, Grimaldi A, Truffer J, Giral P, Doumith R, Therve F, DeGennes JL 1990 Increased serum levels of lipoprotein(a) in diabetes mellitus and their reduction with glycemic control. JAMA 263:35-36

34. Haffner SM, Tuttle K, Rainwater DL 1991 Decrease of lipoprotein(a) with improved glycemic control in IDDM subjects. Diabetes Care 14:302-307

35. Kervinen K, Savolainen MJ, Kesäniemi YA 1991 A rapid increase in lipoprotein(a) levels after ethanol withdrawal in alcoholic men. Life Sci 48:21832188

36. Kostner GM 1990 The physiological role of Lp(a). In: Scanu AM (ed) Lipoprotein(a). Academic Press, San Diego, pp 183-204

37. Iverius PH 1972 The interaction between human plasma lipoproteins and connective tissue glycosaminoglycans. J Biol Chem 247:2607-2613 